\title{
The Impact of Gasfier Stoves Use on Socio-Economic and Environment in Tanzania: The Case of Arusha and Moshi Municipalities
}

\author{
Agnes Godfrey Mwakaje*
}

Institute of Resource Assessment, University of Dar es Salaam, P.O. Box 35097, Tanzania

\begin{abstract}
This study examined the socio-economic and environmental impact of the adoption of gasfier stoves by households in Arusha and Moshi towns in Tanzania. A total of 55 respondents were selected purposely from the gasfier stoves. For comparative purposes another 55 charcoal users were selected randomly for interview making a total sample of 110. There were also focus group consultations and key informant interviews. Structured and semi-structured questionnaires were used to collect data, which were analysed using the Statistical Package for Social Sciences.

The results show that the respondents who were using gasfier stoves had significant reduction $(p=0.001)$ in the cost of energy for cooking compared to charcoal stove users by spending only T.shs 13,396 per month compared to T.shs 36,932 for charcoal users. The use of gasfier stoves also had a positive impact on the environment. Findings show that by using gasfier stoves 15.4 ha were saved from deforestation per annum and about 365.4.tonnes of carbon were saved for sequestration an act that reduces carbon emissions and global warming.

Nevertheless, despite the impressive performance of gasfier stoves for cooking, the rate of adoption has remained low. The main reason for this was reported to be the high price, poor quality of the pellets and unfriendly usability. The adoption of gasfier stoves could only be enhanced by addressing these constraining factors.
\end{abstract}

Keywords: Gasfier stoves, economic and environmental benefits, Tanzania, Sub-Saharan Africa.

\section{INTRODUCTION}

The University of Dar es Salaam under the Policy Innovations System for Clean Energy Security (PISCES) programme has involved in renewable energy technologies since 2007 for a period of six years up to 2013. The Project was funded by the Department for International Development (DFID) of the United Kingdom. The project was implemented in the four countries of India, Kenya, Sri Lanka and Tanzania. The goal of this project was threefold: one, to contribute to the wide transfer of knowledge and understanding of bio-energy; two, to demonstrate policy change in the target countries of the programme; and three, to maximize the contribution of bio-energy to gaining access to clean energy and improved livelihoods.

The PISCES at the University of Dar es Salaam focused its research on the development of biofuel and bio-energy appliances, which could be easily accessed by rural communities. There is a growing interest among researchers and stakeholders in finding out the outcome of the developed technologies by the PISCES-UDSM in relation to the goals of the project.

*Address correspondence to this author at the Institute of Resource Assessment, University of Dar es Salaam, P.O. Box 35097, Tanzania;

Tel: +255 222410 144; Mob: +255 784 391220; Fax: +255222 410393 ;

E-mail: agnes_mwakaje@yahoo.co.uk
The main objective of this paper was to assess the benefits realised by adopting the gasfier stoves and highlight the challenges encountered by users of the stoves in the urban centres of Arusha and Moshi. It also intended to provide insights into the impact of gasfier stoves on deforestation and environmental management. The reasons for the choice of the two urban centres were that, a considerable number of adopters of gasfier stoves were found there, as well as many producers/artisans, which facilitated the implementation of the study and helped to clarify most of the issues raised during the study, and the fact that access to charcoal and fuelwood in these two urban centres is declining due mainly to population growth. The findings from this study will inform policy and decision makers on how best gasfier stoves could be developed and disseminated for wide use and positive impacts, both economically and environmentally. It also informs researchers and artisans the areas of strengths and weaknesses (if any) of the stoves for making improvements. Furthermore it adds to the body of knowledge through publication in the areas of bioenergy, poverty and the environment.

\section{GASFIER STOVE TECHNOLOGY, A LITERATURE REVIEW}

\subsection{Biomass Use}

Although biomass is a renewable source of energy, traditional biomass-fired stoves cause significant 
greenhouse gas emissions due to incomplete combustion which have impact on climate change. Also exposure to smoke from these traditional stoves causes serious health problems [1-3]. While these traditional stoves achieve their purpose of cooking food and other necessities, they also release copious amounts of carbon monoxide and various other poisonous gases [4]. Since people using them often tend to cook their food indoors, they tend to inhale these toxic gases, leading to various respiratory diseases and complexities [4]. These stoves are generally inefficient and their utilization for domestic cooking has been a major contributor to respiratory, other health problems and environmental concerns [2, 5]. Studies show that household indoor air pollution will cause an estimated 9.8 million premature deaths by 2030 [6] and that gradual and rapid transitions to charcoal and petroleum source of energies would delay deaths of people significantly [6]. In this regard, charcoal is regarded as a cleaner energy than fuelwood. Other reasons in favour of charcoal are the high price of oil combined with a sharp decline in foreign exchange earnings, which are key factors influencing the energy sector and access in developing countries especially Africa [7]. Many people cannot use electricity, liquefied petroleum gas or even kerosene for cooking because of high prices.

However, while using charcoal is seen to be better than using firewood in terms of health impacts, its use is also one of the major factors leading to deforestation in developing countries, especially in Sub-Africa. In many regions of the world, particularly in developing countries, the demand for fuelwood can only be met by the over-exploitation of forests [8]. Thus relying on charcoal for cooking carries the risk of continuing deforestation and is a threat to sustainable land use [8]. In Tanzania, a study by Monela et al. [9] revealed that the total area of miombo forest cleared annually for producing charcoal was 4354 hectares or $1524 \mathrm{~km}^{2}$ in 35 years.

Charcoal use has also had an impact on the climate. Charcoal-intensive future scenarios using current practices are estimated to increase emissions by 140 to 190 [6]. Projections of the cumulative impact of business-as-usual in relation to charcoal use show that greenhouse gas emissions will reach 6.7 billion tons of carbon by 2050 , which is $5.6 \%$ of Africa's total emissions [6]. Thus, reducing the demand for charcoal and shifting to other forms of energy could control deforestation [10].
However, as pointed out earlier, it should be noted that the use of charcoal is also a matter of economics. Household energy use varies by income group and local fuel availability [11]. For example, in developing countries like Tanzania, fuelwood and agricultural residue account for $80 \%$ of domestic energy requirements, while commercial energy, such as kerosene, electricity and liquefied petroleum gas, accounts for $1 \%$. Monela et al. [9]. report that a huge area of forest land was cleared in Morogoro Tanzania for charcoal production due to its affordability and efficient fuel for most poor urban dwellers in the country and is a lucrative business with a positive economic impact on charcoal sellers. Nevertheless, this is realized at the expense of environmental management. A transition to renewable energy sources (hydropower, solar, wind and geothermal power as well as biofuels), produced in a sustainable manner, seems to be the only way out of this dilemma [8]. To be adopted, these new energy sources must also have comparative advantage in terms of price relative to alternative sources. Even if the impact of clean energy coming from these sources is high in terms of reducing deforestation and greenhouse gas emissions, without having competitive advantage in terms of price and accessibility, people may still refuse to adopt them.

\subsection{Use of Gasfier Stoves}

Particulate matters emitted from stoves are a big concern to human health and indoor air quality besides carbon monoxide. Generally, alleviating poverty is hindered by two interlinked phenomena: lack of access to improved energy services and worsening environmental shocks due to climate change [12]. As part of the world's move to combat global warming and tackle health issues, developing nations are seeking to reduce their emissions of greenhouse gases emissions, and particularly of carbon dioxide $\left(\mathrm{CO}_{2}\right)$ through the adoption of new energy technologies for cooking [13]. Also the depletion in fossil fuels and an increase in the world's population may change the trend in household kitchens in the future [2]. Mitigating climate change, increasing access to energy and alleviating rural poverty can all be complementary and could lead to sustainable development, their overlap defining an energy-poverty-climate nexus [12].

Studies show that the promotion of technologies, which use biomass more efficiently, could be a key strategy for integrating the concerns of both developing and developed countries in the so called energypoverty-climate nexus [14]. The improved cooking 
stoves programmes implemented in the developing world is an attempt to address these problems [2]. While there are efforts to develop other renewable sources of energy, such as solar and wind power and mini-hydros, there are also problems hindering their development [14].

Modern biomass-based cooking options, such as gasfier stoves, can potentially play an important role in mitigating greenhouse gas emissions from domestic cooking. These sources also provide an alternative to kerosene, natural gas and liquefied petroleum gasfier stoves [1]. Furthermore, they could have an impact on poverty alleviation. The gasfier stoves are more efficient than the traditional stoves [2]. These stoves have been developed using jatropha seeds and rice husks, and have been tested and/or used in many parts of the developing world. The new class of gasfier stoves that have been developed using a single pan are highly efficient with low emissions and promise constant power that can be controlled using any solid biomass fuel in the form of pellets [15].

Literature on gasfier stoves suggests that the use of high density agro-residue-based pellets or coconut shell pieces ensures operational duration of about an hour or more at power levels of $3 \mathrm{kWth}(\sim 12 \mathrm{~g} / \mathrm{min})$ [15]. According to Panwar [16]), the stove exhibits about $35 \%$ thermal efficiency, carbon gases and the stove works in the range of 1.53 to $1.76 \mathrm{~kW}$ of power rating. The overall efficiency of the stove's flame is said to range 50-54 [17]. Nevertheless, it is argued that a comprehensive programme for clean energy should optimise mitigation and, simultaneously, adaptation to climate change while maximising co-benefits for socioeconomic, e.g., through improved air, water and food quality [5]. In the future, biomass has the potential to provide a cost-effective and sustainable supply of energy in developing countries, while at the same time helping countries meet their greenhouse gas reduction targets [18].

\subsection{Biomass Production in the World}

Biomass is the most common form of renewable energy, widely used in the developing world but relative less in the western world [19]. According to Hall et al. [20] biomass is the world's fourth largest energy source and the first in developing countries, representing $14 \%$ and $35 \%$, respectively, of primary energy. Similar findings have been reported by Balat and Ayar [18]. Total biomass resources from natural forests for 1990 were estimated at the equivalency of 27 million tonnes of oil [14]. Latterly, a lot of attention has focused on identifying suitable biomass species, which can provide high-energy outputs, to replace conventional fossil fuel energy sources [19]. Global production of biomass is estimated to be 146 billion metric tons a year, mostly from wild plants and agricultural residuals such as saw mill and sugarcane plantations, and the by-products the sugar, cashew nut, coffee and sisal industries [14]. It has been found that oil palm fronds are the best type of biomass for gasfier stoves and that the higher the carbon content and the calorific value of a biomass, the less time it takes to boil water [2].

However, according to some literature, the success rate of efficiency of biomass energy is marginal compared to the potential available [21]. This limited success is a clear indicator of the need for researches to serious reassess bio-energy programmes. The limitations include the lack of adequate data on the actual energy potential of these sources as well as the lack of local capability to design and manufacture energy-related equipment and spare parts [21].

\subsection{Factors Affecting the Adoption of Clean Energy Technologies by the Poor}

Renewable energy technologies offer an effective means of mitigating climate change, providing access to clean energy by the poor and alleviating poverty. Despite the numerous policies implemented to promote these technologies, the diffusion of renewable energy projects remains somewhat below expectations [22]. Mwakaje [23], suggesting that while right policies are important for clean technology diffusion a consideration of other factors are also important. These may include the absorptive capacity of potential adopters and the age structure of capital [24]. Policy makers also are wary because of the widespread perception that these clean energy technologies cost more than conventional alternatives so that increasing their deployment will raise overall clean energy costs [25]. A study by González [26] revealed a number of factors affecting the adoption of clean energy technologies, which included the conditions of the potential adopters and the characteristics of the environmental technology. Other studies show that adoption rates are higher for projects with shorter paybacks, lower costs, greater annual savings, higher energy prices, and greater energy conservation [27]. Thus, an analysis of the determinants of and barriers to adopting clean technology should be the main goal of economists and social scientists. It should also be the concern of researchers, development partners and environmentalists. 


\subsection{The Conceptual Framework}

Figure 1 presents the conceptual framework for adopting and using gasfier stoves, and the likely impacts. It is assumed that level of awareness, cost of both gasfier stoves and pellets relative to other energy sources in the locality, usability and flexibility, education levels including environmental education, family size, income of the household, age and marital status will influence the level of adoption. It is anticipated that the development and application of cleaner technologies (environmentally friendly technologies) will offer multiple benefits to the adopters. People who adopt gasfier stoves are expected to gain economically in terms of saving money, efficient cooking and positive health impacts through reduced smoke and carbon dioxide emissions. Adopting gasfier stoves is also anticipated to result in environmental gains through reduced deforestation and carbon dioxide emissions [28, 29].

\section{MATERIAL AND METHODS}

\subsection{The Study Area}

\subsubsection{Arusha City}

Arusha City is the headquarters of Arusha region located in northern Tanzania between latitudes $2^{\circ}$ and $6^{\circ}$ south and longitudes $34.5^{\circ}$ and $36^{\circ}$ east. Arusha City is primarily a residential area and vegetation is normally short grass and planted trees. The planted trees are widely spread within the city and are mainly highland species. Older trees are found on traffic islands and alongside major streets in the municipality, which has a total area of $93 \mathrm{~km}^{2}$ (9,300 hectares) out of $34,526 \mathrm{~km}^{2}(0.3 \%)$ of the total area of Arusha region [30].

Arusha city faces socio-economic problems arising from the rapid growth of the urban population attributed to natural growth, rural-urban migration, urban-urban migration and foreign immigrants. It has the highest population density (3,040 people per sq $\mathrm{km}$ ) in the Arusha region. The population is estimated to be 359,044 , although over 100,000 people come into the city in the day time and leave in the evening. The annual inter-census growth rate is estimated to be $5.4 \%$ [31]. The high population influx into Arusha is mainly due to two reasons. First, being a tourist town, the tourism business in Arusha has flourished in recent years and second, the city is the main market for minerals from the Mererani mine (mainly Tanzanite) [30].

The economy of Arusha municipality depends on commerce, industry, small-scale agriculture and tourism. Fifty-two percent of employed people run businesses, $14 \%$ are employed in office work, $17 \%$ are casual labourers and $19 \%$ are in agriculture while the remaining $6 \%$ are employed in industries [32].

Biomass is the main source of energy for the majority of the population in the municipality. Besides biomass, electricity mainly from the national grid and petroleum are also key energy inputs to development sectors within the council. Solar and wind energy in most cases are at the pilot or trial stage. For the past two years, Oikos, an Italian NGO, has been working on

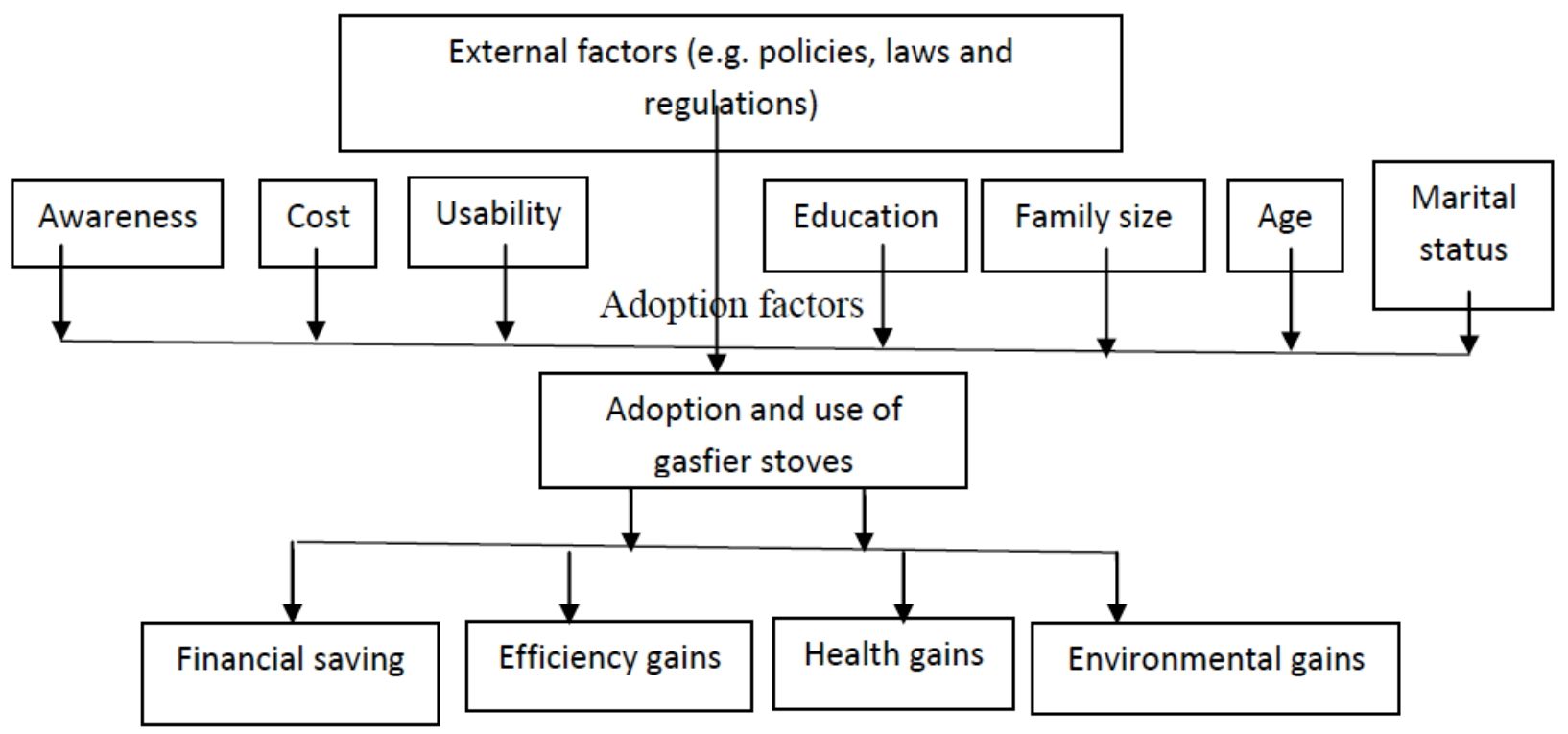

Figure 1: Conceptual framework. 
pilot renewable energy projects in Arusha and Meru District Councils. Also Arusha is the base for a number of organizations involved in the promotion of renewable energies [30]. Traders regard Arusha as a promising strategic centre for the future development of renewable energies due to its booming economic performance resulting from tourism. If there was to be a strong coordinating body, the renewable energy sector would certainly be able to record remarkable achievements and impacts, especially in the rural sector [30]. Available information suggests that the initial cost of establishing the production and use of renewable energy is usually high. However, in the long run operational and maintenance costs are low.

\subsubsection{Moshi Municipality}

Moshi town became a municipality in 1988. It is planned to become a city in 2016. Moshi Municipal Council is located in Kilimanjaro Region and is bordered by Hai district and Moshi Rural District. The Municipal Council covers about 59 sq. km. Administratively, it is divided into 21 wards. According to the 2002 population census, Moshi town had 143,799 people (the night population), which increased to 206,728 people in 2011 .

The day population of Moshi municipality is estimated to be three times the night population. The current night population (2013) is estimated to be 185,190 while the day population is estimated to be 555,570 . The population growth in Moshi municipality is attributed to the high rate of rural-urban migration. The decline in economic activities in rural areas caused by the falling price of coffee and the prolonged drought tend to exacerbate the problem.

The economy of the Council, once a robust one because of the strength of the coffee industry during the 1970s and 1980s, has plummeted, due to both low world prices in the 1990s and low production in the 2000s, which has also been exacerbated by global warming that has wreaked havoc on Mount Kilimanjaro, which it is believed will become snow free by 2029 [33]. Climate experts have warned that this will consequently have an adverse effect on the economy of Kilimanjaro region.

Firewood and charcoal are the main sources of energy for cooking [34]. As a result, deforestation has been rampant in Moshi and the leadership is making concerted efforts to reverse this trend through annual tree-planting campaigns.
Residents of Moshi depend on biomass, especially charcoal, as the main energy for cooking, although a high number use electricity for lighting. This high demand for biomass for cooking raises the concern of deforestation and degradation and its consequent impact on the climate. Developing clean energyefficient technologies could reduce most of these threats.

\subsection{Data Collection}

Both primary and secondary data were collected. Secondary data were collected from similar earlier studies found on the internet and in government reports, and from NGOs and artisans. Secondary data helped to familiarize the researcher with the study and to identify key issues for fieldwork. Since gasfier stove technology is relatively new, the selection of the respondents was purposive, i.e. the researcher talked only to gasfier stove users who were willing to participate in the interviews. For comparison purposes another 55 charcoal users were selected randomly for interviews, making a total of 110 respondents. There was also a discussion with key informants and focus groups, which included the producers of gasfier stoves and pellet manufactures, as well as the sellers of both pellets and stoves and the users of gasfier stoves.

To collect data, structured questionnaires were used to gather detailed information from the users of gasfier stoves while semi-structured questionnaires and checklists were used to collect information from focus groups and key informants. There was also physical observation of the performance of gasfier stoves. Data were analysed using SPSS, START and Excel programmes and are presented in tables and figures.

\subsection{Model for Factors Influencing Charcoal Adoption}

In this study it is hypothesized that the willingness to pay (WTP) for adoption of gasfier stoves will depend on a number of factors, including income, age, family size, education, cost of buying the stove, family size and duration of the stove. That is,

$W T P=\beta_{0}+B_{1} X i+\beta_{2} X e+\beta_{3} X_{a}+B 4 X_{f}+B 5 X_{p}+B 6 X_{d}$ $+\mathrm{e}$

Where: WTP is the dependent variable involving the WTP for a gasfier stove

B's= coefficients to be estimated 
$\mathrm{Xi}=$ household income $(\mathrm{Tsh})$

$\mathrm{Xe}=$ respondent's level of formal education (in years)

$\mathrm{X}_{\mathrm{a}}=$ respondent's age (in years),

$X_{f}=$ family size (persons)

$X_{p}=$ price of the stove (T.shs)

$X_{d}=$ duration (in years)

$\mathrm{e}=$ random error

\subsection{Environmental Impact of Gasfier Stove Use}

Using the study by Van Asperen [35], one hectare of miombo produces $35 \mathrm{~m}^{3}$ wood, each of which could be converted into $3,000 \mathrm{kgs}$ of charcoal. Each hectare in a rectangular forest measuring $2.5 \mathrm{~m}$ by $2.5 \mathrm{~m}$ consists of 1618.5 trees Bengwayan [36] study on the other hand, presents that one tree in a tropical climate will sequester atmospheric carbon dioxide at an average of 50 pounds or $22.7 \mathrm{kgs}$ of carbon dioxide per year.

These two illustrations are adopted to compute the environmental impact of gasfier stove adoption in this study.

\section{RESULTS AND DISCUSSION}

\subsection{Socio-Economic Characteristics of the Respondents}

The average age of the respondents was 41.2 years and there was generally not much difference between the two groups. Gasfier stove users had an average age of 41.3 years, while it was 41.1 years for charcoal stove users. The majority of the respondents were female $(79.6 \%)$. This was anticipated as women are the main users of cooking technologies. Also $89 \%$ of the respondents were married (Table 1), $4.5 \%$ were widowed, $4.5 \%$ had never married and $0.9 \%$ were separated. Education-wise, the majority of the respondents had completed form four (30.7\%) and form six $(23.4 \%)$ and $25.9 \%$ had a diploma or degree (Table 1). This is a relatively high level of education compared to the national average where the majority are primary school leavers. Historically, northern regions of Tanzania were the first to receive education from the colonial administration and missionaries and this trend has been maintained to date. Better educated people may understand better the linkages between the forest, access to clean energy, health and environmental management.

Table 1: Socio-Economic Characteristics of the Respondents (\%)

\begin{tabular}{|c|c|c|c|}
\hline & Gasifier $n=55$ & Charcoal $n=55$ & Average $\mathrm{N}=110$ \\
\hline \multicolumn{4}{|l|}{ Sex } \\
\hline Female & 70.9 & 89.1 & 80 \\
\hline Male & 29.1 & 10.9 & 20.0 \\
\hline \multicolumn{4}{|l|}{ Marital Status } \\
\hline Married & 89.1 & 89.1 & 89 \\
\hline Separated & 1.8 & 0 & 0.9 \\
\hline Widow & 3.6 & 5.45 & 4.5 \\
\hline Never married & 3.6 & 5.45 & 4.5 \\
\hline Cohabiting & 1.8 & 0 & 0.9 \\
\hline \multicolumn{4}{|l|}{ Education } \\
\hline Not even Std four & 1.3 & 11.1 & 6.2 \\
\hline Standard 4 & 21.1 & 0 & 10.55 \\
\hline Standard 7 & 5.3 & 0 & 2.65 \\
\hline Form four & 44.7 & 16.7 & 30.7 \\
\hline A-level & 7.9 & 38.9 & 23.4 \\
\hline Diploma/Degree & 18.4 & 33.3 & 25.9 \\
\hline Masters & 1.3 & 0 & 0.65 \\
\hline
\end{tabular}

Source: Survey data 2012. 
Table 2: Main Economic Activities (\%)

\begin{tabular}{|c|c|c|c|}
\hline Education & Gasifier $\mathbf{n = 5 5}$ & Charcoal $\mathbf{n = 5 5}$ & Average $\mathbf{n = 1 1 0}$ \\
\hline \hline Employee & 43.6 & 43.6 & 43.6 \\
\hline Own business & 50.9 & 29.1 & 40 \\
\hline Farming & 5.6 & 16.4 & 2.25 \\
\hline Fishing & 0 & 4.5 & 2.25 \\
\hline Housewife & 0 & 4.5 & 0.9 \\
\hline Unemployed & 0 & 1.8 & \\
\hline
\end{tabular}

Source: Survey data 2012.

\subsection{Main Economic Activities}

The findings show that the majority of the respondents $(43.6 \%)$ were employed, followed by those who were running their own businesses (40\%) (Table 2). A comparison between the two groups shows that more gasfier stove users were employed $(43.6 \%)$ or running own businesses $(50.9 \%)$ than charcoal stove users, who were $43.6 \%$ and $40 \%$, respectively.

\subsection{Income Levels}

Overall, a high proportion of the respondents in both groups were earning T.shs 500,000 to $1,000,000$ $(57.3 \%)$, followed by those earning between T.shs $1,000,001$ and T.shs 1, 500, 000 (28.7\%). In both groups the percentage of respondents earning less than T.shs 500,000 was small (4.5\%). As regards those earning over T.shs $1,500,000$, the findings show that there were more gasfier stove users (14.6\%) than charcoal users (4.5\%). Also the gasfier stove users earning between T.shs 1,000,000 and above T.shs $1,500,000$ comprised $41.9 \%$, compared to $34.5 \%$ for charcoal stove users (Table 3 ).

\subsection{Comparative Analysis of Energy Costs and Savings}

The findings shows that the quantity of pellets consumed per month, the cost of cooking energy per month and savings per year were all statistically significant at $p=0.001$. An analysis of the cost of energy per month for the two groups shows that gasfier stove users were saving almost two-thirds more than charcoal users (Table 4). The gasfier stove users were spending T.shs 13, 396 for cooking compared to T.shs 36,932 by charcoal stove users. The cost of energy per annum was T.sh 160,754 and 443,189 for gasfier and charcoal stove users, respectively. Overall, gasfier stove users were saving T.shs 282,435 per annum compared to charcoal users (Table 4). These findings are consistent with what had been reported by Sulaiman and Romli [2], Mukunda [15], and Varunkumar [17], who all confirmed that gasfier stoves using agricultural pellets were more efficient than those using other biomass such as charcoal and fuelwood.

A multiple regression model was used to determine the significance of the factors influenced the purchase of gasfier stoves and the results are displayed in Table 5. The findings show that household income was positively and statistically significant $(p=0.001)$ in influencing the willingness to purchase gasfier stoves. This confirms what was reported earlier by Hosier and Kipondya [11] who reported that household energy use varies with income group. This suggests that people with relatively high incomes could take the risk of adopting new technologies while the poor are normally risk averse, and will only adopt a new technology when they are convinced that it works, as learned from

Table 3: Income Levels (T.shs)

\begin{tabular}{|c|c|c|c|}
\hline T.shs & Gasifier $\mathbf{n = 5 5}$ & Charcoal $\mathbf{n = 5 5}$ & Average N=110 \\
\hline \hline Average income & $986,486(82199)$ & $984,095(61574)$ & $984,980(69517)$ \\
\hline$<500000$ & 3.6 & 5.4 & 4.5 \\
\hline $500000-1000000$ & 54.5 & 60 & 57.3 \\
\hline $1000001-1500000$ & 27.3 & 30.1 & 28.7 \\
\hline
\end{tabular}

Figure in parenthesis indicates standard deviation. Source: Survey data 2012. 
Table 4: The Cost of Cooking Per Month

\begin{tabular}{|c|c|c|c|}
\hline & $\begin{array}{c}\text { Gasifier } \\
n=55\end{array}$ & $\begin{array}{c}\text { Charcoal } \\
n=55\end{array}$ & Significance \\
\hline Quantity used per month & $35.6(11.6)$ & $69.6(24)$ & $* * *$ \\
\hline Cost of energy per month & $\begin{array}{l}13396 \\
(3580)\end{array}$ & $\begin{array}{c}36,932 \\
(8550)\end{array}$ & $* * *$ \\
\hline Cost of cooking per annum & $\begin{array}{c}160754 \\
(40,560)\end{array}$ & $\begin{array}{c}443189 \\
(102,600)\end{array}$ & *** \\
\hline Cost saved by adopting Gasifier stoves & \multicolumn{2}{|c|}{282,435} & \\
\hline
\end{tabular}

*** Statistically significant at $\mathrm{p}=0.001$.

Source: Survey data 2012.

Table 5: Regression Results of the Factors Influencing Gasfier Stove Adoption

\begin{tabular}{|c|c|c|c|c|}
\hline Variable (Dependent) & Std error & Beta & t-value & Sign \\
\hline (Constant) & 53180.54 & & 1.221 & 0.159 \\
\hline Household income & 25855.75 & 0.101 & 2.755 & $0.001^{* * *}$ \\
\hline Education level & 14163.15 & 0.003 & 0.201 & $0.755 \mathrm{NS}$ \\
\hline Age & 208.322 & -0.322 & 3.241 & $0.001^{* *}$ \\
\hline Family size & 103.25 & -0.336 & 3.481 & $0.000^{* * *}$ \\
\hline Price of stove & 25655.67 & -0.123 & 2.541 & $0.004^{* * *}$ \\
\hline Duration (years) & 947.45 & 0.055 & 0.848 & $0.665 \mathrm{NS}$ \\
\hline
\end{tabular}

$\mathrm{R}^{2}=73.5 \%,{ }^{* * *}$ significant at $\mathrm{p}<0.001,{ }^{* \star}$ significant at $\mathrm{p}<0.05 \mathrm{NS}=$ not significant. Source: Survey data 2012.

neighbours or relatives. Studies also show that access to credit and the capacity to bear risk play a big role in the adoption of a new technology [37]. There is evidence that in most of African countries, middleincome families have adopted improved stoves far more quickly than poor families [38]. It can therefore be predicted that the rate of adopting to the developed gasfier stoves will depend on income levels of the households.

On the other hand, age of the respondents, family size and the cost of gasfier stoves were inversely related to the respondents' willingness to purchase gasfier stoves at $p=0.05, p=0.001$ and $p=0.001$, respectively. This implies that as the age of a person increases the willingness to adopt new technologies decreases because old people generally find it difficult to change. Also as family size increases the willingness to adopt gasfier stoves decreases, probably due to concern about the ability of the stoves to handle the cooking of large meals, and also arguments within families as to whether or not they should adopt gasfier stoves could affect the rate of adoption. Also the results show that as the cost of gasfier stoves increases the willingness to purchase decreases. According to the producers, the price at which break even can be achieved is T.shs 40,000 . The selling price of T.shs 20,000 was therefore subsidised by $50 \%$. This intended to raise awareness and promote the technology. However, as will be seen later in the paper, only 3.3\% of the respondents are willing to purchase a stove at the cost of T.shs 40,000 .

The $R^{2}$ value of $73.5 \%$ implies that $73.5 \%$ of the variation that occurs in the adoption of gasfier stoves was explained by the independent variables in the model, while $26.5 \%$ of the variation was not explained by the model. These findings support the literature cited earlier in that adoption rate increases with shorter paybacks, lower costs, greater annual savings and greater energy conservation [27].

\subsection{Environmental Benefits}

The average daily consumption of charcoal in the two study areas was estimated to be $2.3 \mathrm{kgs}$ per household. With the sample size of 55 households using gasfier stoves, it means about $46,172.5 \mathrm{kgs}$ of charcoal were saved per annum (Table 6). Based on 
Van Asperen [35] this is equivalent to saving 15.4 ha of forest been saved from deforestation per annum Van Asperen [35] also indicates that one hectare consist 1614.5 trees, for 15.4ha it means 24, 910.1 trees were saved from felled down for charcoal production. Based on Bengwayan [36] study this is equivalent to 365.4 tons of carbon been saved for sequestration and reduction in carbon emissions. Extrapolation of these results to the total households in the study areas would have a remarkable impact on environment. Available information shows that the two towns have a total of 800,497 people [34] with an average family size of 3.8 , results into 210,657 households in the two urban centres of Arusha and Moshi. Assuming that $80 \%$ of these dwellers (or 168525.6 households) in the two urban centres are using charcoal for cooking this means $141,477,241.2 \mathrm{kgs}$ of charcoal are consumed there per annum in Arusha and Moshi urban centres, respectively. According to Van Asperen [35], one hectare of miombo produces $35 \mathrm{~m}^{3}$ wood, each of which could be converted into $3,000 \mathrm{kgs}$ of charcoal. This means that clearing the forest for charcoal use in the two urban areas could result in 47,159 hectares deforested per annum.

According to Van Asperen [35], one hectare of a rectangular forest measuring $2.5 \mathrm{~m}$ by $2.5 \mathrm{~m}$ consists of 1618.5 trees. If 47,159 hectares are cleared per annum, it means that $76,327,660$ trees are felled each year. One tree in a tropical climate will sequester atmospheric carbon dioxide at an average of 50 pounds or $22.7 \mathrm{kgs}$ of carbon dioxide per year [36]. This means that by cutting down 76,327,660 trees for charcoal use in Arusha and Moshi, 1,732,638 tonnes of carbon would be lost, which would have an impact on global warming (Table 6). Adopting gasfier stoves that use pellets and other industrial and agricultural byproducts could reduce these problems connected with tree cutting and climate change. This confirms the literature reported earlier that by reducing the demand for charcoal and shifting to other forms of energy could control deforestation [10].

\subsection{Factors Constraining the Use of Gasfier Stoves}

The findings from this study suggest that the adoption of gasfier stoves by households has both economic and environmental benefits, despite this fact; the adoption rate has remained minimal Ruiz-Mercado [39] commented that no stove programme can achieve its goals unless people initially accept the stoves and continue using them on a long-term basis. In this study the factors that affect gasfier stove adoption were investigated and the results are presented in the following sections.

\subsubsection{Cost of Gasfier Stoves}

The developed gasfier stoves will only be adopted if they are affordable. Most of the respondents bought gasfier stoves at the subsidized price of T.shs 20,000, while the market price is T.shs 40,000 , meaning they paid only $50 \%$ of the actual price. An investigation into whether they would be willing to pay for gasfier stoves if there was a slight increase in the price from T.shs 20,000 to T.shs 25,000 showed that as many as $98.4 \%$ would still be willing to pay for the stoves. However, an increase in the price by T.shs 10,000 from the current price, i.e. from T.shs 20,000 to T.shs 30 , 000, the percentage of respondents who would be willing to buy the stoves decreased to $63.5 \%$ (Figure 2). When the price increased to T.shs 40,000 , which is the breakeven point, only $3.2 \%$ of the respondents would be willing to buy the stoves. These findings imply that for this technology to be adopted, a subsidy is necessary of at least T.shs 10,000 to bring it down to the price of T.shs 30,000 . Alternatively, further innovative research is required to come up with affordable products. Another way of addressing this problem could be that

Table 6: Impact of Gasfier Stoves on Reduction in Deforestation and $\mathrm{CO}_{2}$ Emissions

\begin{tabular}{|c|c|c|}
\hline & Sample for gasfier stove users & Total HH in Arusha and Moshi \\
\hline \hline Population estimates as per 2012 & 55 & 168525.6 \\
\hline Charcoal consumption per day per HH & 2.3 & 2.3 \\
\hline Charcoal consumption per annum (kgs) 80\% & 46172.5 & $141,477,241$ \\
\hline Ha deforested due to charcoal use (at a rate of 3000kgs per ha) * & 15.4 & 47,159 \\
\hline Trees felled & 24910.1 & $763,269,766$ \\
\hline Carbon sequestration capacity lost per year(tons) & 565.4 & $1,732,622$ \\
\hline
\end{tabular}

*van Aspen 2001.

Source: Survey data 2012. 


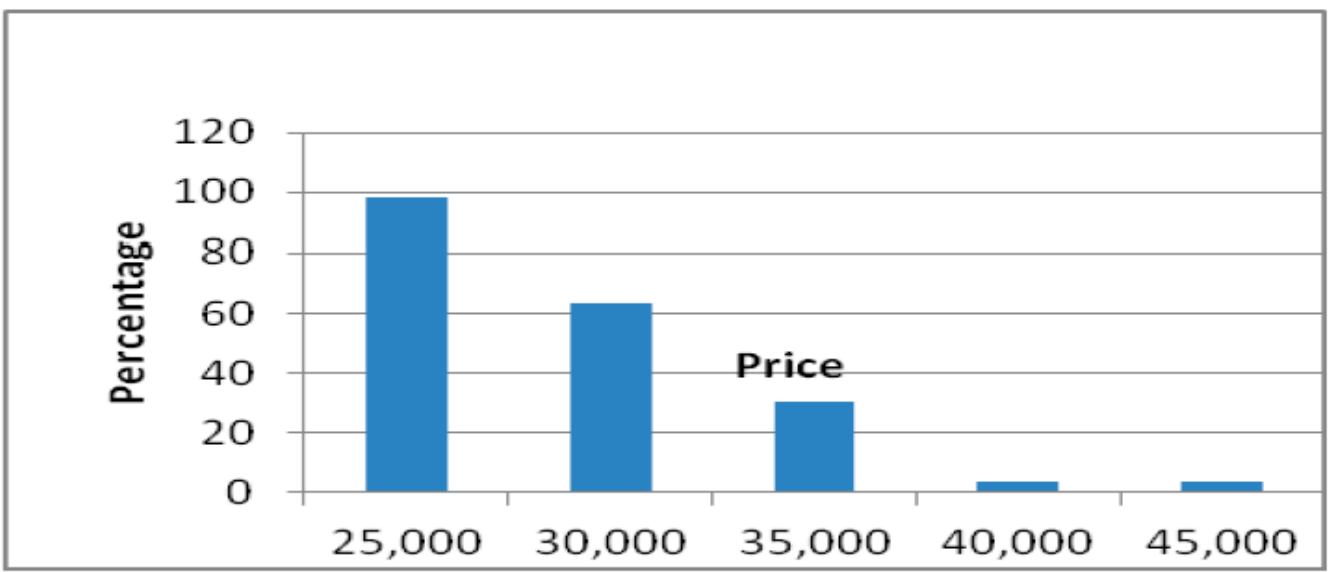

Figure 2: Willingness to pay for gasifier stoves (T.shs). Source: Survey data.

the government, in collaboration with stakeholders, could identify the poorest segment of urban consumers and provide a subsidy to this group while allowing market forces to rule for the rest of the consumers. This is the strategy used by the electricity service, whereby urban consumers in areas like Dar es Salaam are subsidizing the rural poor and poor regions through the Rural Electrification Authority (REA).

\subsubsection{Smoke Production}

Another limitation of gasfier stoves mentioned by users was smoke, as respondents expressed their dissatisfaction with both the gasfier stoves and the pellets. While most of the respondents were satisfied with the quality of the gasfier stoves with regard to efficiency, nevertheless they expressed dissatisfaction with the smoke emitted by the stoves. It was learnt that the stoves tend to emit a lot of smoke when the pellets are starting to burn and this stops only when they all turn red. However, according to the artisans, it is impossible to prevent smoke emission during the initial stage of burning the pellets. Instead, consumers are advised to take the stoves outside into the open air when starting to burn the pellets so that the smoke disperses easily into the air. The stoves should only be returned to the kitchen when the pellets have turned red.

\subsubsection{Quality and Availability of Pellets}

Another major concern raised by the gasfier stove users was about the availability of pellets, their quality and burning duration. The respondents expressed concern about the supply of pellets as, according to them, only a few centres sell the pellets in the surveyed towns. In addition, the respondents were unhappy with the quality of the pellets in that they are not well compressed and could easily turn to dust if they are not properly handled. Furthermore, the respondents complained that the pellets do not last long when cooking with the stoves and are quickly finished.

Responding to these concerns, the producers explained that the pellets currently in the market are made from jatropha cakes and due to the nature of this feedstock it has been difficult to compress and bind them tightly so that they do not crumble easily. To solve this problem, the producers suggested a new technology that uses maize cobs as feedstock to produce pellets. According to the manufacturers, the pellets made from maize cobs are harder and more tightly bonded and have the capacity to burn for a longer period than those made from jatropha cakes. Moreover, the pellet producers have seen the need to increase the number of agents selling the pellets to gasfier stove users and, to begin with, they have come

Table 7: Pellet Prices (T.shs)

\begin{tabular}{|c|c|c|c|}
\hline & Level of sale & Promotion price & Normal price \\
\hline \hline 1 & Bulk price & 15,000 & 25,000 \\
\hline 2 & Wholesale price & 15,000 & 25,000 \\
\hline 3 & Retail price & 20,000 & 30,000 \\
\hline
\end{tabular}

Source: Survey data 2012. 
up with a new rate of commission for those who would work as their agents (Table 7). They have reduced the price to attract agents and the users of pellets. However, this strategy will only be beneficial if a lot of people adopt the technology and use it. This will depend very much on addressing the highlighted weaknesses.

\subsubsection{Usability}

During the survey it was learned that gasfier stove users still do not know how to control the stove fire through adjusting the door. In most cases they leave the stove door open when cooking, thereby facilitating the burning of the pellets. The door in the stove is meant to control the amount of air entering to burn the pellets. In this case, therefore, the wider the door is opened the higher the burning rate of the pellets and vice versa and the higher the burning rate of the pellets the shorter time the fire will last. This suggests that even if improved pellets are produced, without controlling the air entering the stoves the problem of the pellets finishing quickly will continue. The consumer needs to learn how to properly adjust the amount of air entering the gasfier stoves. Generally, the findings further confirm those of Pachauri and Jiang [40], who identified that the key drivers of the transition to clean energy adoption were income, energy prices, access to energy and local fuel availability

\section{CONCLUSION AND RECOMMENDATIONS}

The main objective of this study was to investigate the socio-economic and environmental impact of gasfier stove adoption in the urban areas of Arusha and Moshi. The major findings are that the stoves are significantly efficient in terms of quantity of pellets used, cost and savings per annum. The study also shows that factors such as income levels are significant in influencing the willingness to adopt the technology. Respondents with relatively high incomes are willing to take risks of adopting the technology. On the other hand, age, family size and price showed an inverse and significant difference in influencing the adoption of gasfier stoves. The study also revealed a significant impact of gasfier stoves use on the environment through reduced deforestation, carbon dioxide emissions and enhancement of carbon dioxide sequestration. Consequently, the author is in agreement with Casillas and Kammen [12] that gasfier stoves have the potential to mitigate climate change, increase access to energy and alleviate rural poverty.

Nevertheless, the adoption of the technology may be constrained by the cost of the stoves, and the quality and availability of pellets. A high proportion of the respondents are unwilling to pay more than T.shs 30,000 per stove while, according to the producers, the break-even price is T.shs 40,000 . Addressing the challenges observed could lead to a higher rate of adoption of the technology and consequently the realization of the diverse benefits of gasfier stoves. Generally, more innovative studies are required by the manufacturers to reduce the price of the stoves and improve the quality of the pellets. It is further recommended that educational and awareness campaigns should be implemented on the benefits of gasfier stoves, financial and non-financial incentives should be provided and an institutional framework for governing renewable energy should be established. The government in collaboration with donors should also consider providing a subsidy for the poor. However, subsidies add costs to the government and therefore should only be implemented after a comprehensive cost and benefit analysis of the policy.

\section{ACKNOWLEDGEMENT}

The author would like to thank all those who have contributed both directly and indirectly to the publication of this paper. Special thanks go to the Policy Innovations System for Clean Energy Security (PISCES) programme for funding of this study. The author is particularly grateful to the Institute of Resource Assessment of the University of Dar es Salaam for granting permission to undertake this study. The valuable comments on the manuscript by Prof Jamidu Katima is highly appreciated. The author is also grateful to $\mathrm{Mr}$ Victor Makundi and Emmanuel Anangisye for their assistance in data collection and entry. However, the views and opinion expressed herein are those of the author and do not necessarily reflect those of the PISCES.

\section{REFERENCES}

[1] Bhattacharya SC, Salam AP. Low greenhouse gas biomass options for cooking in the developing countries. Biomass Bioenergy 2002; 22(4): 305-17.

http://dx.doi.org/10.1016/S0961-9534(02)00008-9

[2] Sulaiman SA, Romli R. Combustion Performance of Various Cellulosic Biomasses in a gasfier Cooking stove. In: 4th International Meeting on Advances in Thermofluids (IMAT) 2011 Melaka. http://eprints.utp.edu.my/6549/. Accessed on $24^{\text {th }}$ January 2013.

[3] Ezzati M, Kammen DM. Quantifying the effects of exposure to indoor air pollution from biomass combustion on acute respiratory infections in developing countries. Environm Health Persp 2001; 109(5): 481-88. http://dx.doi.org/10.1289/ehp.01109481

[4] Bhanap IJ, Deshmukh R. Development of an improved sawdust gasifier stove for industrial applications. J Renewable Sustainable Energy 2012; 4: 16 pages. 
[5] Haines AF, Smith KR Anderson D, Epstein PR, McMichael AJ, Roberts I, et al. Policies for accelerating access to clean energy, improving health, advancing development, and mitigating climate change. Lancet 2007; 370(9594): 1264-28. http://dx.doi.org/10.1016/S0140-6736(07)61257-4

[6] Bailis R1, Ezzati M, Kammen DM. Mortality and Greenhouse Gas Impacts of Biomass and Petroleum Energy Futures in Africa. Science 2005; 308(5718): 98-103. http://dx.doi.org/10.1126/science.1106881

[7] Kammen DM, Kirubi C. Poverty, Energy, and Resource Use in Developing Countries. Annals of the New York Academy of Sciences. Focus on Africa, Reducing the Impact of Poverty on Health and Human Development: Scientific Approaches 2008; 1136: 348-57.

[8] Schulte-Bisping $H$, Bredemeier, M, Beese FO. Global availability of wood and energy supply from fuelwood and charcoal. Ambio 1999; 28(7): 592-94.

[9] Monela GC, O'Kting'ati A, Kiwele PM. Socio-economic aspects of charcoal consumption and environmental consequences along the Dar es Salaam-Morogoro highway, Tanzania. Forest Ecology Management 1993; 58(3-4): 24958.

http://dx.doi.org/10.1016/0378-1127(93)90148-G

[10] Hofstad O. Woodland Deforestation by Charcoal Supply to Dar es Salaam. J Environm Econom Manag 1997; 33(1): 1730.

http://dx.doi.org/10.1006/jeem.1996.0975

[11] Hosier RH, Kipondya W. Urban household energy use in Tanzania: Prices, substitutes and poverty. Urban Energy Environ Africa 1993; 21(5): 454-73.

[12] Casillas CE, Kammen DM Biomass energy: Lessons from case studies in developing countries. Environment and Development. Policy Forum. Science 2010; 330(6008): 118182. http://dx.doi.org/10.1126/science.1197412

[13] Barton JH, Osborbe GE Intellectual Property and Access to Clean Energy Technologies in Developing Countries 2010. http://hdl.handle.net/123456789/28398 Accessed on 14th March 2013.

[14] Kishore VVN, Bhandari PM, Gupta P. Biomass energy technologies for rural infrastructure and village poweropportunities and challenges in the context of global climate change concerns. Energy Policy 2004; 32 (6): 801-10. http://dx.doi.org/10.1016/S0301-4215(03)00002-8

[15] Mukunda HS, Dasappa S, Paul PJ, Rajan NKS, Mahesh Y, Kumar RD, Mukund D. Gasfier stoves - science, technology and field outreach. Curr Sci 2010; 98(5): 627-38.

[16] Panwar N. Design and performance evaluation of energyefficient biomass gasfier cooking stoves with multi fuels. Mitigation Adaptation Strategies Global Change 2009; 14(7): 627-33. http://dx.doi.org/10.1007/s11027-009-9187-4

[17] Varunkumar S, Rajan NKS, Mukunda HS. Experimental and computational studies on a gasfier stove. Energy Conver Manag 2012: 53(1): 135-41.

http://dx.doi.org/10.1016/j.enconman.2011.08.022

[18] Balat M and Ayar G. Biomass Energy in the World, Use of Biomass and Potential Trends. Energy Sources 2005; 27(10): 931-40.

http://dx.doi.org/10.1080/00908310490449045

[19] McKendry P. Energy production from biomass (part 1): overview of biomass. Bio-Resour Technol 2002; 83(1): 3746. http://dx.doi.org/10.1016/S0960-8524(01)00118-3

[20] Hall DO, Rosillo-Calle F, de Groot P. Biomass energy: Lessons from case studies in developing countries. Energy Policy 1992; 20(1): 62-73.

http://dx.doi.org/10.1016/0301-4215(92)90148-U
[21] Ravindranath $\mathrm{NH}$, Balachandra P. Sustainable bio-energy for India: Technical, economic and policy analysis. Energy 2009; 34(8): 1003-13.

http://dx.doi.org/10.1016/j.energy.2008.12.012

[22] Masinia A, Menichetti E. The impact of behavioural factors on the renewable energy investment decision making process: Conceptual framework and empirical findings. Energy Policy 2012; 40: 28-38. http://dx.doi.org/10.1016/j.enpol.2010.06.062

[23] Mwakaje AG. Dairy farming and biogas use in Rungwe district,South-west Tanzania: A study of opportunities and constraints. Renewable Sustainable Energy Rev 2008: 224052.

http://dx.doi.org/10.1016/.j.rser.2007.04.013

[24] Kemp R, Volpi M. The diffusion of clean technologies: a review with suggestions for future diffusion analysis. J Cleaner Produc 2001; S14-S21.

[25] Awerbuch S. Portfolio-Based Electricity Generation Planning: Policy Implications For Renewable Energy Security. Mitigation and Adaptation Strategies for Global Change 2006; 11(3): 693-10.

http://dx.doi.org/10.1007/s11027-006-4754-4

[26] González P. Analysing the factors influencing clean technology adoption: a study of the Spanish pulp and paper industry. Business Strategy Environ 2005; 14(1): 20-37. http://dx.doi.org/10.1002/bse.426

[27] Anderson ST, Newell RG. Information programs for technology adoption: the case of energy-efficiency audits. Resource Energy Econom 2004; 26(1): 27-50. http://dx.doi.org/10.1016/j.reseneeco.2003.07.001

[28] Montalvo C. Cleaner technology diffusion: case studies, modelling and policy. J Cleaner Produc 2008b; 16(1): (Suppl 1): S1-S6.

[29] Montalvo C. General wisdom concerning the factors affecting the adoption of cleaner technologies: a survey 1990-2007. J Cleaner Produc 2008a; 16(1): (Suppl 1): S7-S13.

[30] CASEC. Community Aid and Small Enterprises Consultancy (CASEC). Arusha district council. District energy guideline 2010. Unpublished.

[31] URT. United Republic of Tanzania. National Population and Housing Census 2002: Mkuki Publishers, Dar es salaam, Tanzania.

[32] Paul R. Environmental and social impact statement for the proposed upgrading of $1.73 \mathrm{~km} \mathrm{NMC} \mathrm{-} \mathrm{PPF} \mathrm{road} \mathrm{in} \mathrm{Arusha}$ municipality under the proposed Tanzania strategic cities project 2011. Draft report. M/s UWP Consulting (Pty) Ltd, P. O. Box 1857, Pietermaritzburg, KwaZulu-Natal, 3200, South Africa in association with UWP Consulting (T) Ltd, P.O. Box 8151, Dar Es Salaam. Tel. +255 22 2780341; Fax +255 22 2780362; email info@uwp.co.tz

[33] URT (2007). Moshi Town. (http://www.tanzaniavolunteers. com/staying-and-living/freetime/moshi-town/

[34] URT. United Republic of Tanzania. Moshi Socio-Economic Profile 2012: Unpublished.

[35] Van Asperen S.A. Research Project: Improvement of production and management processes of Metal-Ceramic Charcoal Stoves in Dar es Salaam, Tanzania 2001.

[36] Bengwayan MA. How To Calculate CO2 in Trees 2010 http://michaelbengwayan.wordpress.com/2010/11/08/how-tocalculate-co2-in-trees/. Accessed on 14th March 2013.

[37] Giné X, Klonner S. Credit Constraints as a Barrier to Technology Adoption by the Poor: Lessons from SouthIndian Small-Scale Fishery 2005, World Bank and Cornell University.

[38] Jones DW. Some Simple Economics of Improved Cookstove Programs in Developing Countries. Resour Energy 1989; 10: 24764. 
[39] Ruiz-Mercado I, Masera O, Zamorac H, Smith KR. Adoption and sustained use of improved cooking stoves. Energy Policy 2011; 39 (12): 7557-7566.

http://dx.doi.org/10.1016/..enpol.2011.03.028
$[40]$

Pachauri S, Jiang L. The household energy transition in India and China. Energy Policy 2008; 36(11): 4022-35.

http://dx.doi.org/10.1016/j.enpol.2008.06.016 